\title{
ROLE OF MRI AND DIFFUSION MRI IN EVALUATION OF PELVIC MASSES OF GYNAECOLOGICAL ORIGIN
}

\author{
Richard Semelka, Khaled Shawky, Saeed AbdelMoniem, Heba F. Tantawy \\ Radiology department, faculty of medicine, \\ Zagazig University, Egypt
}

Objective: is to highlight the role of diffusion weighted MRI in evaluation of gynecologic pelvic masses especially in differentiation between benign and malignant masses, and initial staging of known malignancies.

Design: Randomized controlled study.

Setting: zagazig university hospitals radiology department and university of North Carolina, MRI unit.

Participant(s): Women undergoing investigations for pelvic masses.

Intervention(s): Ultrasound examination, MRI and diffusion MRI with Quantitative measurement of the apparent diffusion coefficient (ADC).

Main Outcome Measure(s): DWI and ADC values provide additional information in the differentiation between benign and malignant masses.

Results: Although the ADC can help to differentiate between normal and cancerous tissue in the uterine cervix and endometrium. In patients with ovarian cancer, DWI demonstrates high intensity not only at the primary cancer site but also in disseminated peritoneal implants. When added to conventional MRI findings,

Conclusion: DWI and ADC values provide additional information to routine pelvic MRI and improve the specificity of MRI and thus increasing the radiologist's confidence in image interpretation which will finally reflect on the patients' outcome and prognosis, but it should be in conjunction with conventional MRI sequences.

Keywords Diffusion. ADC. Magnetic resonance imaging. Uterus. Ovary.

\section{INTRODUCTION}

$\mathbf{M}$ RI has been shown to be superior to $\mathrm{CT}$ in the work-up of uterine and cervical cancer and may be a useful problem-solving tool in the evaluation of ovarian cancer (1).

Diffusion-weighted magnetic resonance (MR) imaging is a functional imaging technique whose contrast derives from the random motion of water molecules within tissues and its use has been established as a useful functional imaging tool in neurologic applications for a number of years, but recent technical advances now allow its use in abdominal and pelvic applications (2).

Diffusion-weighted imaging is not only helpful in differentiating benign from malignant processes within the myometrium and endometrial cavity but it can also be used to assess metastatic lesions, peritoneal dissemination, possible tumor recurrence, and treatment response (3).

Because image contrast is derived from inherent differences in the restriction of the movement of water molecules, \& does not require injection of a gadolinium-based contrast agent, so it can be used in patients with renal insufficiency or contrast material allergy (2).

The diffusion of water molecules is affected by the extent of tissue cellularity and the presence of intact cell membranes. As a result, tissues with low cellularity and defective cell membranes have relative increase in extracellular space allowing free water diffusion. On the other hand, in highly cellular tissues (as in viable tumors) water diffusion is restricted because of reduced extracellular space and by intact cell membranes, which act as barrier to water movement (4).

Most of the malignant tumors are generally depicted as areas of high signal intensity on DWI and dark on the ADC map (pattern of restricted diffusion), unlike areas with simple T2 prolongation (e.g, edema or fluid), which will demonstrate high signal intensity on both the diffusion-weighted images and the ADC map. (3).

Benign tumors and most of the fibromas did not show this abnormal signal intensity on DWI (5).

However, mature cystic teratomas can exhibit increased signal intensity either entirely or focally on DWI with corresponding significant low ADC values. This may be attributed to sebaceous or keratinous materials respectively. This may improve diagnostic performance where there is a paucity of fat (6).

DW-MRI shows restriction of movement of water molecules in endometrial cancer with increased signal intensity particularly at high bvalues and corresponding low signal intensity on ADC maps (5). DWI may be an additional tool for distinguishing uterine sarcomas from benign leiomyomas. The ADC values $(\times 10-3 \mathrm{~mm} 2 / \mathrm{s})$ of uterine sarcomas (1.17) were lower than those of the normal myometrium (1.62) and degenerated 
leiomyomas (1.70) without any overlap; however, they were overlapped with those of ordinary leiomyomas (0.88) and cellular leiomyomas (1.19) Because ordinary leiomyomas tend to contain hyalinized collagen, the signal intensity of ordinary leiomyomas is hypotintensity on T2weighted images. DWI can be explained with "T2 blackout effect", which indicates hypointensity on DWI caused by hypointensity on T2-WIs, resulting in a decrease in the ADC of ordinary leiomyomas (7).

Differentiation of the post-operative changes from the residual tumors might be possible in the early period in some cases with the help of DWI showing lack of tissue restriction with corresponding high ADC values, where areas of edema or inflammation can show high ADC values while low ADC values will suggest the presence of active tumor cells $(\mathbf{8})$.

\section{PATIENTS AND METHODS}

This study was performed on 100 cases of female pelvic masses. Apart from 13 examined cases, all examined cases have undergone surgery with pathologic correlation after MR imaging.

The study was conducted in zagazig university radiology department and university of North Carolina, maternity and female hospital. The patients were referred from the gynecology department to the radiology department (MR imaging unit) in the period from January 2011 to September 2014.

The patients' age ranged from 16 to 65 year old (mean age $44.44 \pm 12.77 \mathrm{SD}$ ).

Most of the patients presented by abnormal vaginal bleeding, abdominal enlargement, long standing abdominal pain, 25 were presented by offensive vaginal discharge, four came with other different complaints; one came complaining with frequency of micturition, dysuria, loss of weight and one was complaining from dyspnea and was accidentally discovered during routine follow up examination.

\section{All cases had been subjected to the following:}

- Full history taking (Age, Parity, Time of menopause, Past history of gynecological troubles or operations and Positive family history of gynecological malignancy.

- Routine laboratory investigation for all patients including $\mathrm{CBC}$, random blood sugar, liver functions and kidney functions. 3 patients do Serum B-HCG and CA-125 was done for most of the patients.

- Ultrasound examination: All patients had undergone preliminary pelvic ultrasound to exclude benign functional pure cystic lesions.The examination was done on ultrasound machine GE logic 7, trans-abdominal and trans-vaginal ultrasound approaches using 3-4 $\mathrm{MHz}$ and 7-8 $\mathrm{MHz}$ probes respectively. Color Doppler was superimposed on masses to detect vascularity.

- MR imaging was performed on a 1.5-T MR imaging unit (Achievia, Philips medical system). All the patients were imaged in the supine position using pelvic phased-array coil. Patients fast for 3 hours. Intravenous administration of an antispasmodic drug (10 $\mathrm{mg}$ of [Visceralgine; Organon, Livron, France]) was given immediately before MR imaging to reduce bowel peristalsis.

\section{MR Imaging protocol:}

The sequences used in the study are axial, sagittal and coronal T2 WIs, and T1 axial, T1 axial gradient, Post contrast axial T1 was done in some patients. DWI at b0 and b1000 and ADC map.

\section{MR Imaging analysis:}

MR images were analyzed for the following:

-Site of the lesion, uterine body, cervix, Involvement of one or both ovaries, or vagina.

-MR appearance of the tumor; whether cystic, solid or mixed.

-Signal intensity of the tumor.

-Enhancement of the solid component if present.

-Wall thickness of the tumor and its enhancement.

-Presence of vegetations, their enhancement pattern and their size.

-Presence of ascites.

-Presence of infiltrated pelvic or para aortic lymph nodes.

-Involvement of other pelvic organs.

-Presence of peritoneal and omental deposit.

-Prescience of parametrial invasion.

-Post contrast images were used for the recognition of enhancement of the solid component, the tumor wall, septations and vegetations.

\section{Interpretation of DWI:}

Qualitative analysis

Regarding the signal intensity: Benign tumors show no signal on DWI, while malignant ones show high signal intensity on high $b$ values ( $>$ $1000 \mathrm{sec} / \mathrm{mm} 2$ ) with corresponding lowering of the signal in the corresponding ADC maps. Both, the solid component of the tumors as well as the cystic component were measured in the ADC maps by careful drawing of the ROI's in order to include the largest possible solid part in both solid and mixed tumors for the qualitative analysis.

Regarding Suspicious lymph nodes and peritoneal deposits especially in presence of ascites, we searched for lesions (on peritoneal surfaces or at sites of lymph node deposits) with restricted diffusion, i.e. high signal on DWI similar to that seen in malignant tumors. 


\section{Quantitative analysis:}

Regarding the quantitative analysis of DWI, we generated the ADC maps from the DWI from $b$ values $(0,500$, and 1000$)$, then we selected the ROI manually on the largest possible area of the solid and the cystic component of the tumors, which was then automatically calculated on the work station to get the different ADC values.

\section{RESULTS}

100 patient was included in our study. They are divided into two groups according to the site of origin of the mass group A patients with ovarian masses $(n=37)$ and group B patients with extra ovarian masses $(n=63)$. Comparisons of differences in the categorical data between groups were performed using the Chi-square $(\chi 2)$ test. Comparison of the continuous variables were achieved by the Mann-Whitney U (MW) test for two groups of non-parametric data, Student t-test for two groups of normally distributed data.

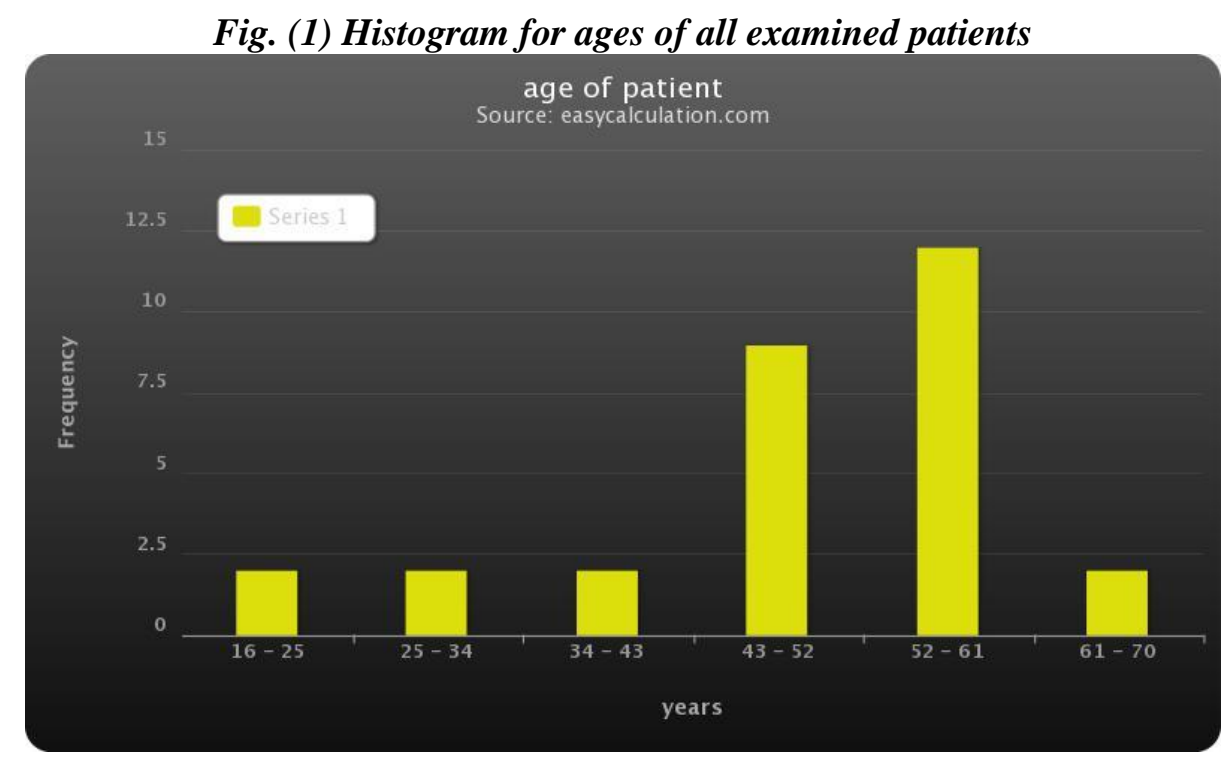

Fig. 2: Histogram for all studied cases in correlation with post-operative pathological diagnosis as a golden standard

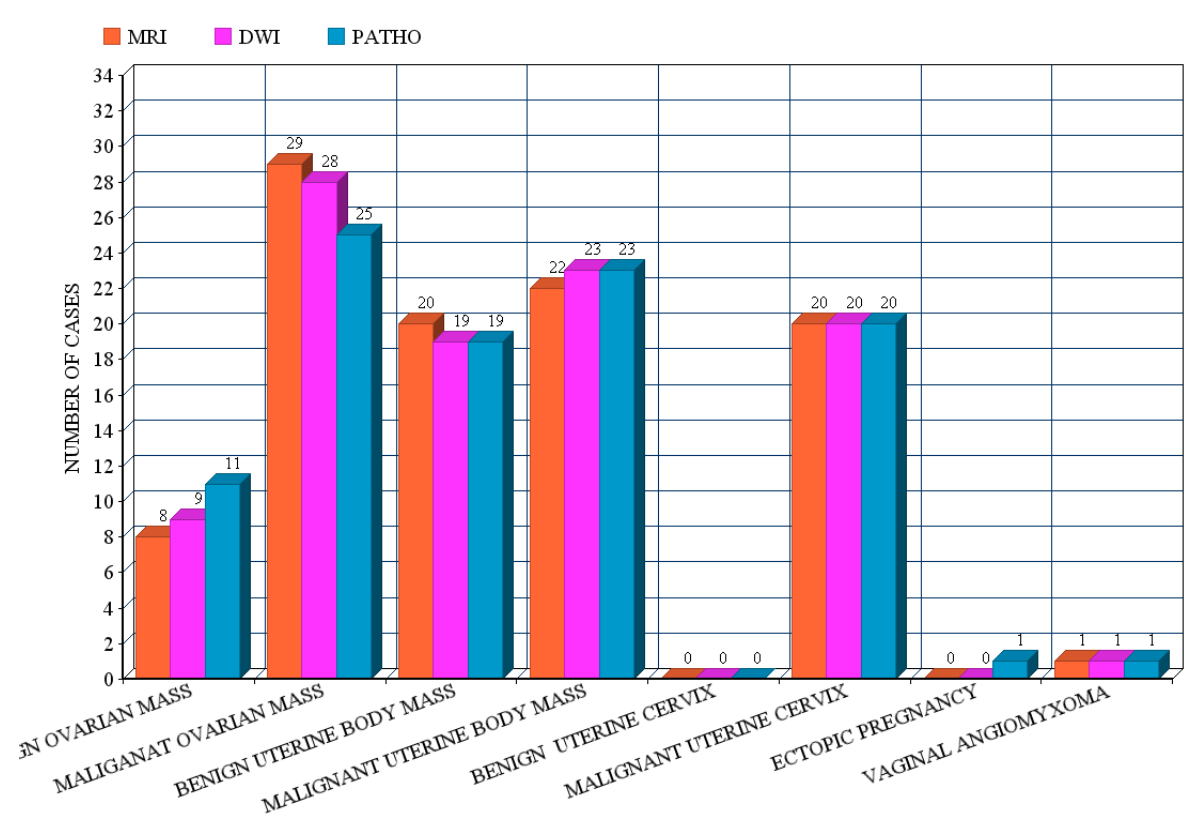

Fig. 3: Pie chart of Group A based on histo-pathological diagnosis 


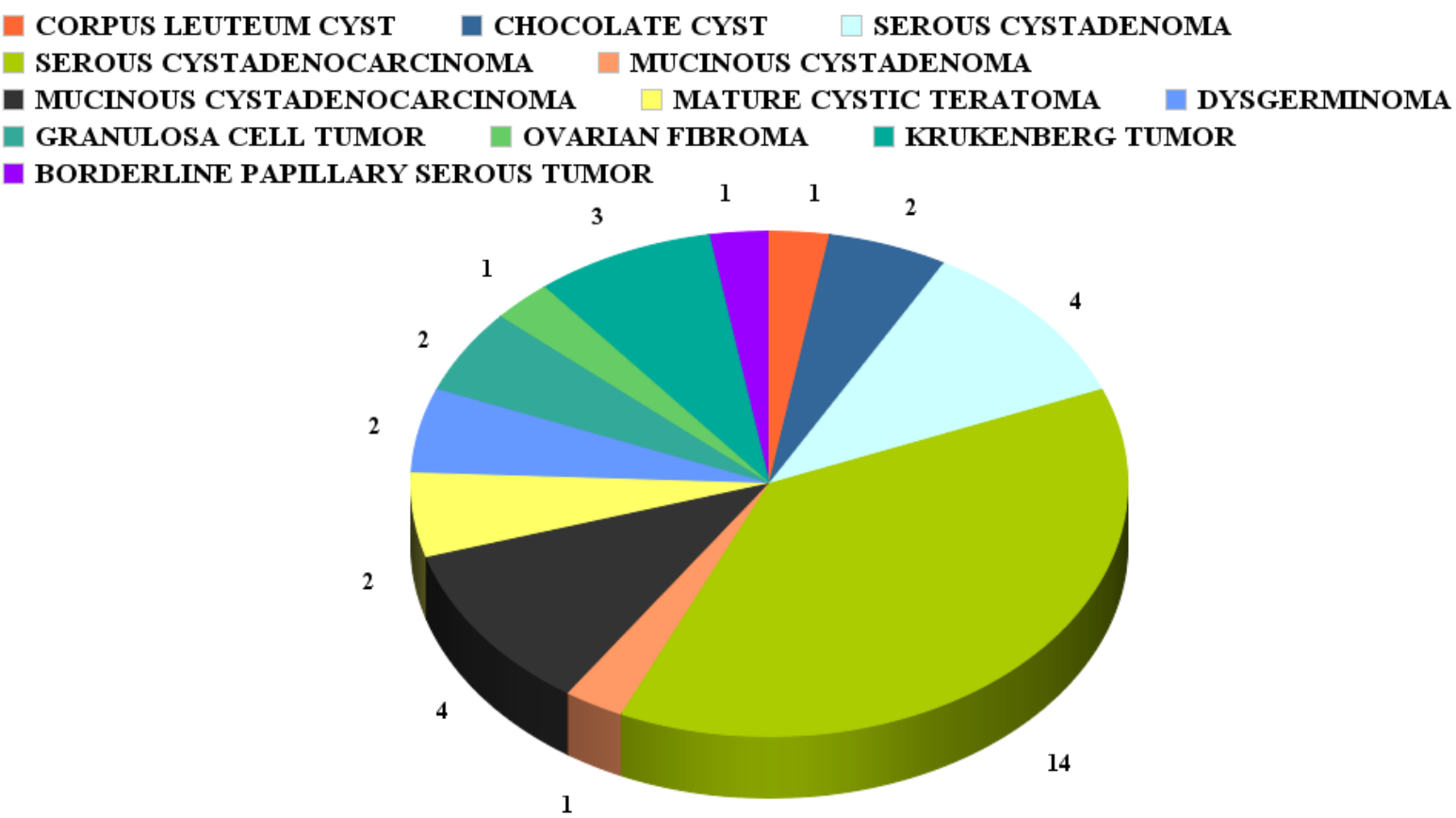

Fig. 4: Pie chart of Group B based on histo-pathological diagnosis *cervical cases are out of chart - Cervical Squamous Cell Carcinoma a Cervical Adenocarcinoma a vaginal myxoma $\quad$ choriocarcinoma - Vesicular mole $\quad$ Ectopic pregnancy Endometrial Hyperplesia $\quad$ Endometrial clear cell carcinoma

Endometrial Adenocarcinoma $\quad$ uterine fibroid $\quad$ degenerated subserous fibroid

low grade leiomyosarcoma

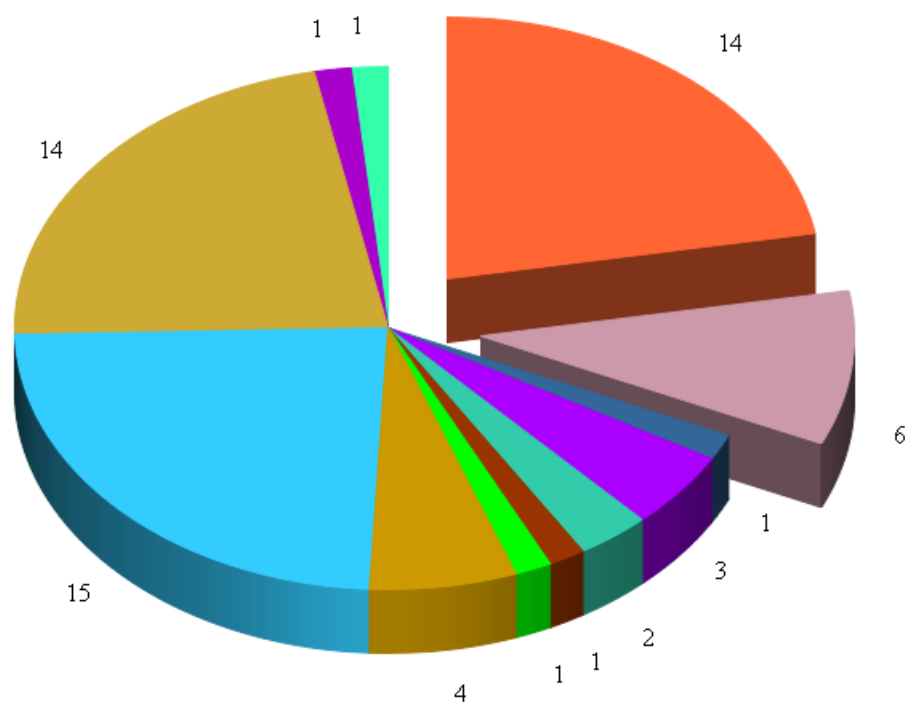


Table (1) characteristic findings of conventional MRI in correlation with post-operative histopathology of group A patients with ovarian masses $(N=37)$

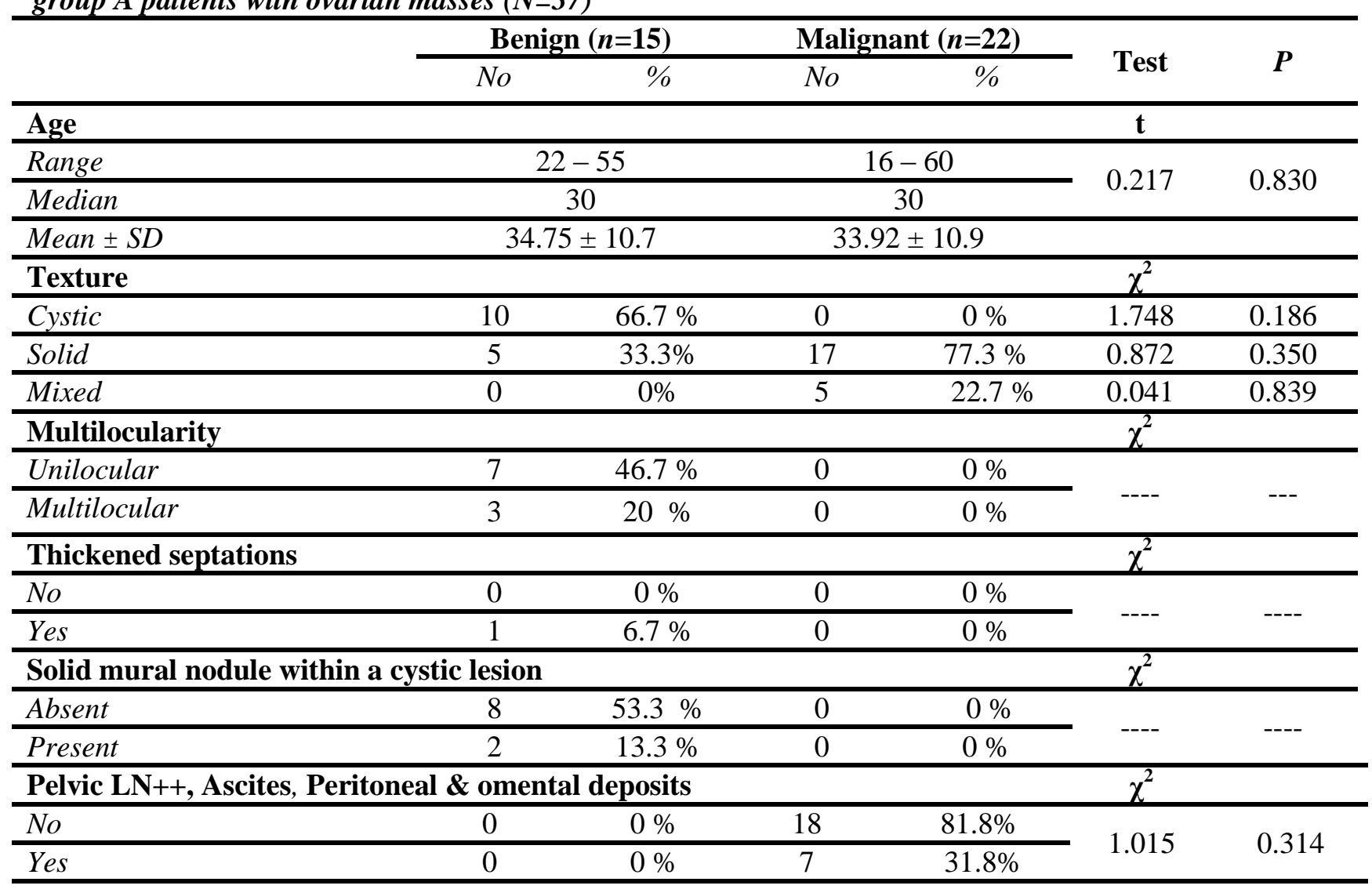

Table (2) Logistic regression analysis for Conventional MRI predictors of malignant ovarian masses $(N=37)$

\begin{tabular}{lccccc}
\hline & $\begin{array}{l}\text { Regression } \\
\text { Coefficient }\end{array}$ & SE & OR & 95\% CI & $p$ \\
\hline Pelvic LN++ & +17.9296 & 3000.8 & 0.000 & $0.000-0.000$ & 0.9952 \\
\hline Solid nodule & +2.2380 & 0.8898 & 9.3750 & $1.6391-53.6225$ & $\mathbf{0 . 0 1 1 9 *}$ \\
\hline Constant & -0.2231 & --- & --- & --- & --- \\
\hline $\begin{array}{l}\text { Overall Mod el Fit: } \text { Chi-square } \\
\text { The model correctly classified } 72.97 \% \text { of cases }\end{array}$ & & & \\
\hline
\end{tabular}


Table (3) Characteristic of Conventional MRI findings with correlation of post-operative histopathology in group B 'patients with extraovarian masses" (N=63)

\begin{tabular}{|c|c|c|c|c|}
\hline & Benign $(n=20)$ & Malignant $(n=43)$ & \multirow{2}{*}{ Test } & \multirow{2}{*}{$P$} \\
\hline & $\mathrm{No}$ & $\mathrm{No}$ & & \\
\hline Age & & & MW & \\
\hline Range & $35-55$ & $35-65$ & & \\
\hline Mean $\pm S D$ & $40.35 \pm 5.55$ & $55.16 \pm 7.30$ & 56.5 & $0.000 *$ \\
\hline Median & 40 & 55 & & \\
\hline \multicolumn{5}{|l|}{ Texture } \\
\hline Normal & $5 \%$ & $0 \%$ & 0.156 & 0.692 \\
\hline Cystic & $15 \%$ & $0 \%$ & 1.784 & 0.181 \\
\hline Solid & $70 \%$ & $100 \%$ & 6.127 & 0.013* \\
\hline Mixed & $10 \%$ & $0 \%$ & 0.156 & 0.692 \\
\hline Dimensions & & & \multicolumn{2}{|c|}{ MW } \\
\hline Range & $3-13 \times 3-10$ & $2-11 \times 2-10$ & \multirow{3}{*}{$\begin{array}{l}300 \\
194\end{array}$} & \multirow{3}{*}{$\begin{array}{c}0.052 \\
\mathbf{0 . 0 0 0} *\end{array}$} \\
\hline Mean $\pm S D$ & $7.6 \pm 3.6 \times 7.4 \pm 2.2$ & $5.5 \pm 2.3 \times 5.2 \pm 2.1$ & & \\
\hline Median & $7.5 \times 8$ & $5 \times 5$ & & \\
\hline Pelvic LN++ & & & \multicolumn{2}{|l|}{$\chi^{2}$} \\
\hline $\mathrm{No}$ & $100 \%$ & $86 \%$ & \multirow{2}{*}{3.084} & \multirow{2}{*}{0.079} \\
\hline Yes & $0 \%$ & $14 \%$ & & \\
\hline
\end{tabular}

Table (4) Logistic regression analysis for Conventional MRI predictors of malignant Extraovarian masses $(N=63)$

\begin{tabular}{lccccc}
\hline & $\begin{array}{l}\text { Regression } \\
\text { Coefficient }\end{array}$ & SE & OR & 95\% CI & $p$ \\
\hline Pelvic LN++ & +18.8594 & 4079.0 & 0.000 & $0.000-0.000$ & 0.9963 \\
\hline Constant & +1.7492 & -- & --- & --- & -- \\
\hline $\begin{array}{l}\text { Overall Model Fit: Chi-square at 3 degree of freedom } \\
\text { The model correctly classified } 71.43 \% \text { of cases }\end{array}$ \\
\hline
\end{tabular}


Table (5) Group A Correlation of Diffusion weighted MRI findings and post-operative histopathology of ovarian origin $(N=37)$

\begin{tabular}{|c|c|c|c|c|}
\hline & Benign $(n=12)$ & Malignant $(n=15)$ & \multirow{2}{*}{ Test } & \multirow{2}{*}{$\boldsymbol{P}$} \\
\hline & No & No & & \\
\hline$\overline{\text { DWI }}$ & & & \multicolumn{2}{|l|}{$\overline{\chi^{2}}$} \\
\hline Decrease (Facilitated) & $58.3 \%$ & $0 \%$ & \multirow{2}{*}{17.986} & \multirow{2}{*}{$0.000^{*}$} \\
\hline Increase (Restricted) & $41.7 \%$ & $100 \%$ & & \\
\hline ADC & & & \multicolumn{2}{|l|}{$\overline{\chi^{2}}$} \\
\hline Decrease SI & $41.7 \%$ & $0 \%$ & \multirow{2}{*}{17.986} & \multirow{2}{*}{$0.000 *$} \\
\hline Increase SI & $58.3 \%$ & $100 \%$ & & \\
\hline \multicolumn{2}{|c|}{ ADC value (ROI) on cystic component } & & \multicolumn{2}{|l|}{ MW } \\
\hline Minimum & 0.390 & 0.710 & \multirow{5}{*}{45.5} & \multirow{5}{*}{$0.014 *$} \\
\hline Maximum & 3.200 & 1.090 & & \\
\hline Mean $\pm S D$ & $1.794 \pm 0.856$ & $0.995 \pm 0.374$ & & \\
\hline Median & 1.98 & 0.900 & & \\
\hline 95\% Confidence Interval & $1.218-2.369$ & $0.808-1.181$ & & \\
\hline \multicolumn{2}{|c|}{ ADC value (ROI) on solid component } & & \multicolumn{2}{|l|}{$\mathbf{t}$} \\
\hline Minimum & 1.100 & 0.400 & \multirow{5}{*}{1.766} & \multirow{5}{*}{0.326} \\
\hline Maximum & 2.100 & 1.100 & & \\
\hline Mean $\pm S D$ & $1.600 \pm 0.707$ & $0.714 \pm 0.183$ & & \\
\hline Median & 1.600 & 0.700 & & \\
\hline 95\% Confidence Interval & $-4.753-7.953$ & $0.638-0.7902$ & & \\
\hline
\end{tabular}

Table (6) Logistic regression analysis for Diffusion weighted MRI predictors of malignant ovarian masses $(N=37)$

\begin{tabular}{lccccc}
\hline & $\begin{array}{l}\text { Regression } \\
\text { Coefficient }\end{array}$ & SE & OR & 95\% CI & $p$ \\
\hline $\begin{array}{l}\text { ADC value on cystic } \\
\text { component }\end{array}$ & -2.032 & 0.778 & 0.131 & $0.029-0.602$ & $\mathbf{0 . 0 0 9 *}$ \\
\hline Constant & +3.215 & --- & --- & --- & --- \\
\hline $\begin{array}{l}\text { Overall Model Fit: Chi-square at 6 degree of freedom }=23.356 ; \\
\text { The model correctly classified } 79.3 \% \text { of cases }\end{array}$ & & & & \\
\hline
\end{tabular}


Table (7) Group B Correlation of Diffusion weighted MRI findings and post-operative histopathology of Extraovarian mass $(N=63)$

\begin{tabular}{|c|c|c|c|c|c|c|}
\hline & \multicolumn{2}{|c|}{ Benign $(n=20)$} & \multicolumn{2}{|c|}{ Malignant $(n=43)$} & \multirow{2}{*}{ Test } & \multirow[b]{2}{*}{$\boldsymbol{P}$} \\
\hline & $\mathrm{No}$ & $\%$ & $\mathrm{No}$ & $\%$ & & \\
\hline DWI & & & & \multicolumn{3}{|c|}{$\overline{\chi^{2}}$} \\
\hline Decrease (Facilitated) & 17 & $95 \%$ & 0 & $0 \%$ & \multirow{2}{*}{58.490} & \multirow{2}{*}{$0.000 *$} \\
\hline Increase (Restricted) & 2 & $5 \%$ & 43 & $100 \%$ & & \\
\hline \multicolumn{7}{|l|}{ ADC } \\
\hline Decrease & 16 & $80 \%$ & 43 & $100 \%$ & 7.969 & 0.004* \\
\hline Increase & 1 & $5 \%$ & 0 & $0 \%$ & 1.861 & 0.172 \\
\hline$I S O$ & 3 & $15 \%$ & 0 & $0 \%$ & 3.869 & 0.049* \\
\hline ADC value (ROI) on cystic & & & & & \multicolumn{2}{|l|}{ MW } \\
\hline Minimum & \multicolumn{2}{|c|}{1.500} & \multirow{4}{*}{\multicolumn{2}{|c|}{---}} & \multirow{4}{*}{ NA } & \multirow{4}{*}{ NA } \\
\hline Maximum & \multicolumn{2}{|c|}{2.270} & & & & \\
\hline Median & \multicolumn{2}{|c|}{1.500} & & & & \\
\hline Mean $\pm S D$ & \multicolumn{2}{|c|}{$1.666 \pm 2.888$} & & & & \\
\hline $95 \%$ Confidence Interval & \multirow{2}{*}{\multicolumn{2}{|c|}{$0.949-2.383$}} & & & \multirow{2}{*}{\multicolumn{2}{|c|}{ MW }} \\
\hline ADC value (ROI) on solid & & & & & & \\
\hline Minimum & \multicolumn{2}{|c|}{0.850} & \multicolumn{2}{|c|}{0.600} & \multirow{5}{*}{119} & \multirow{4}{*}{$0.000 *$} \\
\hline Maximum & \multicolumn{2}{|c|}{1.800} & \multicolumn{2}{|c|}{1.140} & & \\
\hline Mean $\pm S D$ & 1.000 & .285 & 0.81 & .108 & & \\
\hline Median & & & & & & \\
\hline 95\% Confidence Interval & 0.85 & 142 & 0.7 & 833 & & \\
\hline
\end{tabular}

Table (8) Logistic regression analysis for diffusion weighted MRI predictors of malignant Extraovarian masses $(N=63)$

\begin{tabular}{lccccc}
\hline & $\begin{array}{l}\text { Regression } \\
\text { Coefficient }\end{array}$ & SE & OR & $\mathbf{9 5 \%}$ CI & $\boldsymbol{p}$ \\
\hline$A D C$ & -0.07428 & 1.2354 & 0.9284 & $0.0824-10.4559$ & 0.9521 \\
\hline$A D C$ value & -7.4155 & 3.3197 & 0.0006 & $0.000-0.4030$ & $\mathbf{0 . 0 2 5 5 ^ { * }}$ \\
\hline Constant & +7.2520 & --- & --- & --- & --- \\
\hline $\begin{array}{l}\text { Overall Model Fit: Chi-square at 2 degree of freedom } \\
\text { The model correctly classified } 72.13 \% \text { of cases }\end{array}$ & & & \\
\hline
\end{tabular}


Table (9) Correlation of Diffusion weighted MRI findings and post-operative histopathology of pelvic mass $(N=100)$

\begin{tabular}{|c|c|c|c|c|c|c|}
\hline & \multicolumn{2}{|c|}{ Benign $(n=36)$} & \multicolumn{2}{|c|}{ Malignant $(n=64)$} & \multirow{2}{*}{ Test } & \multirow{2}{*}{$\boldsymbol{P}$} \\
\hline & No & $\%$ & No & $\%$ & & \\
\hline \multicolumn{4}{|l|}{$\overline{D W I}$} & & \multicolumn{2}{|l|}{$\chi^{2}$} \\
\hline Decrease (Facilitated) & 32 & 88.8 & 0 & 0 & \multirow{2}{*}{74.662} & \multirow{2}{*}{$0.000 *$} \\
\hline Increase (Restricted) & 4 & 11.2 & 64 & 100 & & \\
\hline \multicolumn{5}{|c|}{ ADC value (ROI) on cystic component } & \\
\hline Mean $\pm S D$ & \multicolumn{2}{|c|}{$1.766 \pm 0.761$} & \multicolumn{2}{|c|}{$0.995 \pm 0.374$} & \multicolumn{2}{|l|}{$\mathbf{T}$} \\
\hline Median & \multicolumn{2}{|c|}{1.890} & \multicolumn{2}{|c|}{0.900} & \multirow{4}{*}{3.478} & \multirow{4}{*}{$0.003 *$} \\
\hline Minimum & & & & & & \\
\hline Maximum & & & & & & \\
\hline $95 \%$ Confidence Interval & 1.32 & & 0.8 & & & \\
\hline \multicolumn{5}{|c|}{ ADC value (ROI) on solid component } & \\
\hline Mean $\pm S D$ & \multicolumn{2}{|c|}{$1.060 \pm 0.365$} & \multicolumn{2}{|c|}{$0.768 \pm 0.145$} & \multicolumn{2}{|l|}{ MW } \\
\hline Median & \multicolumn{2}{|c|}{0.870} & \multicolumn{2}{|c|}{0.780} & \multirow{4}{*}{200.5} & \multirow{4}{*}{$0.000 *$} \\
\hline Minimum & \multicolumn{2}{|c|}{0.850} & \multicolumn{2}{|c|}{0.400} & & \\
\hline Maximum & \multicolumn{2}{|c|}{2.100} & \multicolumn{2}{|c|}{1.140} & & \\
\hline $95 \%$ Confidence Interval & \multicolumn{2}{|c|}{$0.889-1.231$} & \multicolumn{2}{|c|}{$0.733-0.803$} & & \\
\hline
\end{tabular}

Table (10) Mean Pelvic Mass ADC performance on cystic component; ROC curve Analysis

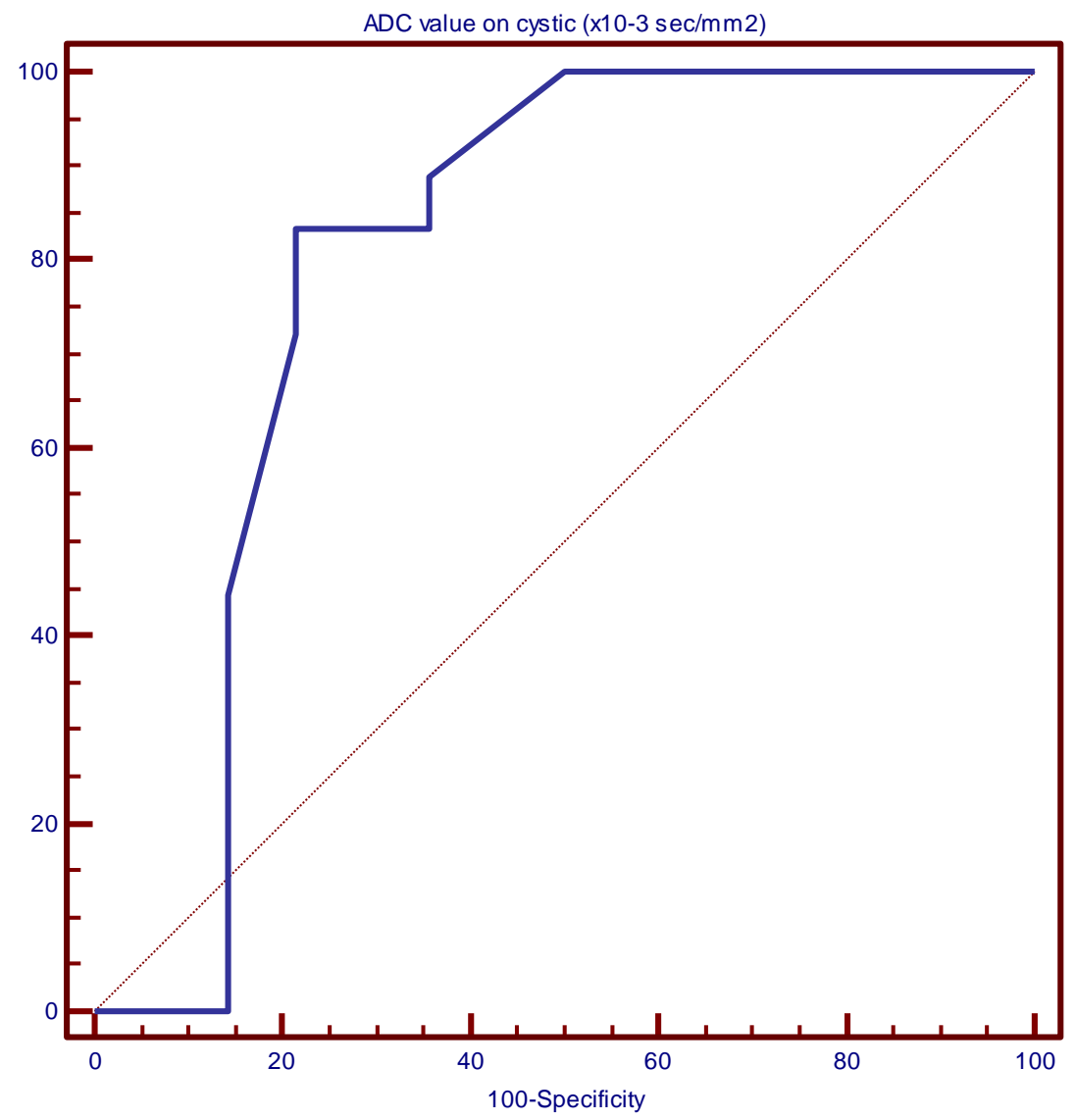




\begin{tabular}{lccccc}
\hline $\begin{array}{c}\text { Cut-off values } \\
\left(\times \mathbf{1 0}^{-3} \mathbf{s} / \mathbf{m m}^{2}\right)\end{array}$ & $\begin{array}{c}\text { Sens. \% } \\
(95 \% \mathrm{CI})\end{array}$ & $\begin{array}{c}\text { Spec. \% } \\
(95 \% \mathrm{CI})\end{array}$ & $\begin{array}{c}\text { PPV \% } \\
(95 \% \mathrm{CI})\end{array}$ & $\begin{array}{c}\text { NPV \% } \\
(95 \% \mathrm{CI})\end{array}$ & $\begin{array}{c}\text { AUC* } \\
(95 \% \mathrm{CI})\end{array}$ \\
\hline$\leq \mathbf{1 . 3}^{\mathbf{a}}$ & $83.3 \%$ & $78.6 \%$ & $83.3 \%$ & $78.6 \%$ & $0.796 \%$ \\
& $(58.6-96.4)$ & $(49.2-95.3)$ & $(58.6-96.4)$ & $(49.2-95.3)$ & $(0.616-0.917)$ \\
\hline$<\mathbf{0 . 3 9}^{\mathbf{b}}$ & $0 \%$ & $100 \%$ & --- & $43.7 \%$ & \\
& $(0.0-18.5)$ & $(76.8-100)$ & - & $(26.4-62.3)$ & \\
\hline
\end{tabular}

a Screening cut-off value

b Diagnostic cut-off value

* Accuracy of Mean Pelvic Mass ADC performance on cystic component $=$ Fair $\$ p=0.0025$

Table (11) Mean Pelvic Mass ADC performance on solid component; ROC curve Analysis

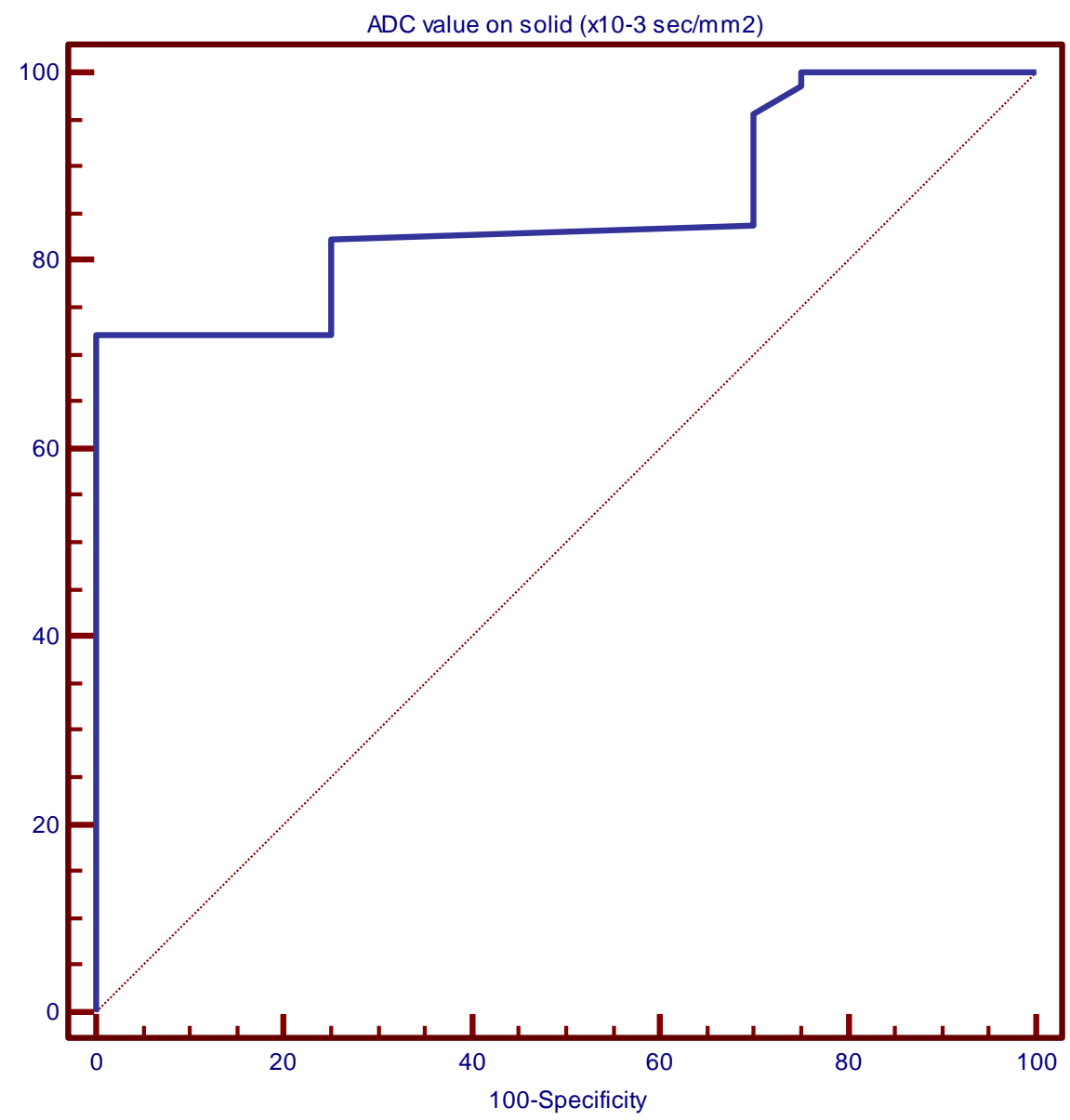

\begin{tabular}{lccccc}
\hline $\begin{array}{c}\text { Cut-off values } \\
\left(\times \mathbf{1 0}^{-3} \mathbf{s} / \mathbf{m m}^{2}\right)\end{array}$ & $\begin{array}{c}\text { Sens. \% } \\
(95 \% \mathrm{CI})\end{array}$ & $\begin{array}{c}\text { Spec. \% } \\
(95 \% \mathrm{CI})\end{array}$ & $\begin{array}{c}\text { PPV \% } \\
(95 \% \mathrm{CI})\end{array}$ & $\begin{array}{c}\text { NPV \% } \\
(95 \% \mathrm{CI})\end{array}$ & $\begin{array}{c}\text { AUC* } \\
(95 \% \mathrm{CI})\end{array}$ \\
\hline$\leq \mathbf{1 . 1 4}^{\mathbf{a}}$ & $100 \%$ & $25 \%$ & $81.9 \%$ & $100 \%$ & \\
& $(94.7-100)$ & $(8.7-49.1)$ & $(72-89.5)$ & $(47.7-100)$ & $0.853 \ddagger$ \\
\hline$<\mathbf{0 . 8 0}^{\mathbf{b}}$ & $72.1 \%$ & $100 \%$ & $100 \%$ & $51.3 \%$ & $(0.761-0.919)$ \\
& $(59.9-82.3)$ & $(83.2-100)$ & $(92.6-100)$ & $(34.8-67.6)$ & \\
\hline
\end{tabular}

a Screening cut-off value

b Diagnostic cut-off value

* Accuracy of Mean Pelvic Mass ADC performance on solid component = Good $\$ \mathrm{p}<0.0001$ 


\section{DISCUSSION}

In this study, the sensitivity of MRI was $98.46 \%$ and DWI MRI was $100 \%$. The specificity was $90 \%$ in both DWI and conventional MRI sequences and so addition of DWI to the MRI is expected to increase the sensitivity of examination.

Regarding the mean ADC values for ovarian solid malignant lesions was $(0.714 \times 10-3 \pm 0.183$ SD $\mathrm{mm} 2 / \mathrm{s}$ ), while that for solid benign lesions was $(1.600 \times 10-3 \pm 0.707 \mathrm{SD} \mathrm{mm} 2 / \mathrm{s})$, with $\mathrm{p}$ value $=0.326$, however $\mathrm{p}$ value was considered < 0.05 of statistical significance. With $95 \%$ Confidence Interval $=0.638-0.7902$

A comparative study was carried out by Fujii and colleagues in 2008 on 123 ovarian lesions including 42 malignant and 81 benign lesions, most malignant ovarian tumors as well as some of the mature cystic teratomas showed high signal intensity on DWI. In contrast, most benign tumors did not show abnormal signal intensity on DWI. This agree with our results where we have 25 malignant tumors and two cases of mature cystic teratomas showed high signal on DWI, this may be attributed to keratinoid substance and Rokitansky protuberance.

Also those authors concluded that the mean ADC value of the solid portion in malignant tumors did not significantly differ from that in the benign lesions (5) .In this study, we also did not find a significant difference between the mean ADC value of benign cystic component (was $1.766 \pm 0.761 \times 10-3 \mathrm{~mm} 2 / \mathrm{s})$ or solid component (was $1.060 \pm 0.365 \times 10-3 \mathrm{~mm} 2 / \mathrm{s}$ ) and the malignant solid (was $0.768 \pm 0.145 \times 10-3 \mathrm{~s} / \mathrm{mm} 2$ ) or cystic (was $0.995 \pm 0.374 \times 10-3 \mathrm{~s} / \mathrm{mm} 2$ ) component.

In 2009, Thomassin-Naggara et al evaluated the contribution of DWI in conjunction with morphological criteria to characterize 77 complex adnexal masses (30 benign and 47 malignant).In their results, low signal intensity both on DWI and T2-weighted images in the solid component of mixed adnexal masses may predict benignity (9). This result matched with our result.

Another study was carried out by $\mathrm{Li}$ and colleagues in 2011 on 127 patients with pelvic masses, (46 benign and 85 malignant). The purpose of this study was to evaluate differences in ADC values for the solid component of benign and malignant ovarian surface epithelial tumors with the goal of differentiating benign versus malignant ovarian tumors preoperatively. The mean ADC value measured for the cystic component did not differ significantly between benign and malignant masses. Unlike that measured for the solid component which significantly differed between the benign and malignant lesions. According to a study done by $\mathrm{Li}$ and colleagues in 2011, Mean ADC value for benign lesions was $1.69 \times 10-3 \pm 0.25 \times 10-3$ $\mathrm{mm} 2 / \mathrm{s}$, and for the malignant was $1.03 \times 10$ $3 \pm 0.22 \times 10-3 \mathrm{~mm} 2 / \mathrm{s}$. The lower ADC values associated with the malignant group were found to be statistically significant. Their results suggest that an ADC value $\geq$ $1.25 \times 10-3 \mathrm{~mm} 2 / \mathrm{s}$ may be an optimal cutoff value for differentiating benign and malignant ovarian tumors (10).

In our study, the mean ADC value for solid malignant lesions was $(0.768 \times 10-3 \pm$ $0.145 \mathrm{SD} \mathrm{mm} 2 / \mathrm{s}$ ), while that for solid benign lesions were $(1.060 \mathrm{x} 10-3 \quad \pm 0.365 \mathrm{SD}$ $\mathrm{mm} 2 / \mathrm{s})$. However, no statistical difference for the solid component between the malignant and benign lesions ( $\mathrm{p}$ value $=$ 0.003 ) with a statistical significant $\mathrm{p}$ value < 0.05 . This may be attributed to the small no of our benign cases and due to the marked lowering of ADC values of some benign tumors as two cases of mature cystic teratomas. Also in their study, the sensitivity, specificity, PPV, NPV and accuracy of conventional MR imaging all have increased from $91.8 \%, 78.3 \%, 88.6 \%, 83.7 \%$, and $87.0 \%$ respectively to $96.5 \%, 89.1 \%, 94.3 \%$ ,93.2\% , and $93.1 \%$ after adding DWI to the conventional MR. This was comparable to our study.Addition of DWI to conventional raises the specificity, PPV, NPV and accuracy from $78.6 \%, 62.5$, and $91.7 \%$ to $83.3 \%, \quad 78.6 \%$, and $92.3 \%$ with no improvement for the sensitivity.

A similar study was carried out by Takeuchi and colleagues at 2010 on 47 women (33 malignant, 6 borderline, and 10 benign tumors).Regarding the signal intensity, the solid portion of all malignant tumors showed homogeneous or heterogeneous high intensity on DWI, whereas only 3 of the benign tumors (3 thecomas) showed high intensity. However the presence of low intensity on T2-weighted images was suggestive for benign fibrous tumor. In our study all benign tumors including the ovarian fibroma did not show high signal on the DWI (except for the mature cystic teratoma tumors). The mean (SD) ADC value in malignant tumors $1.03 \mathrm{x}$ 10-3 (0.19) $\mathrm{mm} 2 / \mathrm{s}$ was significantly lower 
than that and in the 10 benign tumors 1.38 $\times 10-3 \mathrm{~s} / \mathrm{mm} 2 \quad(0.30)$. Using a cutoff ADC value of 1.15 , malignant lesions had a sensitivity of $74 \%$, specificity of $80 \%$, PPV of $94 \%$, and NPV of $44 \%$. Using a cutoff ADC value of 1.0, malignant lesions had a sensitivity of $46 \%$, specificity of $100 \%$, PPV of $100 \%$, and NPV of $32 \%$. In our study the mean ADC value in malignant ovarian tumors $0.80 \times 10-3 \mathrm{~s} / \mathrm{mm} 2$, in benign ovarian cystic lesion $1.09 \times 10-3 \mathrm{~s} / \mathrm{mm} 2 \quad(0.19)$. Using cutoff ADC value of 1.14, malignant lesions had a sensitivity of $94.7-100 \%$, specificity of $25 \%$, PPV of $81.9 \%$, and NPV of $100 \%$. Using a cutoff ADC value of 0.8 , malignant lesions had a sensitivity of $72.1 \%$, specificity of $100 \%$, PPV of $100 \%$, and NPV of $51.3 \%$.

In 2011, Bharwani N. et.al, show that both the mean and minimum ADC values of endometrial carcinoma are significantly lowers than those of benign endometrial histology (11). This finding is in agreement with our study as there was no overlap in mean ADC value between benign and malignant lesions and in other studies only a small degree of overlap in values with the difference remaining statistically significant. Previous studies have suggested mean ADC cut-off values that can be used to predict malignancy in endometrial lesions. These mean ADC cut-off values range from 1.0561023 to $1.261023 \times 10-3 \mathrm{~mm} 2 / \mathrm{s}$ When applied this data on our patients we achieved sensitivity, specificity, PPV, NPV and accuracy rates of $100 \%, 22.225,75.4 \%$ and $100 \%$, respectively. It is difficult to establish a universal threshold ADC value above which malignancy should be suggested owing to variations in the MRI system used and the number of $b$ values used to generate the ADC map.

The ADC threshold value with the greatest accuracy for our 1.5T Philips system $(1.14 \times 10-3 \mathrm{~s} / \mathrm{mm} 2)$ is of the same order of magnitude as the prior values and the variation between values is up to $0.23 \times 10-3$ $\mathrm{mm} 2 / \mathrm{sec}$.

There are some limitations to our study. Firstly, this preliminary cohort of patients is relatively small. Secondly, some of the tumors we analyzed were small and only present on two contiguous slices. In these cases the ROI was placed on the slice with the largest area of visible tumor; however, as tumor was not present on the section above and below, it is possible that the data are subject to some partial volume effect.

Naganawa Sh. and coauthors in 2005 said that the ADC numeric value of cervical cancer is significantly lower than of the unaffected cervical tissue (12).

The ADC threshold value for differentiating cancer-damaged tissue with unaffected cervical tissue: it was $1.100 \times 10$ $3 \mathrm{~mm} 2 / \mathrm{s}$ in the study of Charles-Edwards and co-authors, $1.359 \times 10-3 \mathrm{~mm} 2 / \mathrm{s}$ in the work of Chen and colleagues (13), and 1.28 $\times 10-3 \mathrm{~mm} 2 / \mathrm{s}$ in the research of Chen et al. (14), In our study, the ADC threshold value for differentiating between cancer-affected and non-affected cervical tissues was $0.786 \times$ $10-3 \mathrm{~mm} 2 / \mathrm{s}$. $\pm 0.083 \mathrm{SD}$. According to data of our investigation, the ADC numerical value is significantly lower than of the unaffected cervical tissue

\section{Few cases were challenging in our study.}

- The first one is the mature cystic teratomas. This tumor showed a misleading appearance on the DWI, with the lowering of both signal on the DWI and ADC values in the ADC maps, giving a picture similar to a malignant tumor. Fortunately, most of the teratomas can be easily diagnosed by the conventional images with the help of the fat suppressed images.

- The second case was the borderline papillary serous cystadenoma. The preoperative diagnosis of BOTs remains challenging regarding the clinical, laboratory and imaging findings. Women with BOTs is thought to be as twice as women with invasive cancers to be asymptomatic and are usually diagnosed accidentally on routine examination. Although CA-125 is elevated in up to $61 \%$ of women with BOT, their levels might overlap between women with BOT and those with stage I invasive ovarian cancers (15). In our study, although DWI could alert us for the possibility of a borderline tumor which was confirmed by pathology, this was found only in one case (only one case of borderline tumor in our study).

- The third case was low grade leiomyosarcoma with enlarged uterine fibroid, it shows an abnormal heterogeneous suspicious enhancement pattern and appears as high SI lesion on DWI and iso on ADC map with ADC value was $1.17 \times 10-3 \mathrm{~mm} 2 / \mathrm{s}$ which alerts us for the possibility of malignancy which was confirmed by 
pathology, this was found only in one case (only one case of low grade leiomyosarcoma in our study).

- The last one was a misleading case with a misleading history, it was an illegal ectopic pregnancy, MRI findings are coexisting with a large degenerated subserous fibroid. DWI show a restricted diffusion with ADC value in two different levels was 1.17 and $0.99 \times 10$ $3 \mathrm{~mm} 2 / \mathrm{s}$ which is more with malignancy. Postoperative data revealed that it was an ectopic pregnancy.

\section{CONCLUSION}

The combination of DWI to conventional MRI implies:

- Using a completely noninvasive technique with no radiation exposure.

- DWI might be an alternative for contrast administration especially for those were contrast intake is better avoided as during pregnancy.

- Cost effective technique (no additional cost to MRI examination), easily added to the MR study protocols with no marked lengthening of examination time.

- It improves the specificity of MRI and thus increasing the radiologist's confidence in image interpretation which will finally reflect on the patients' outcome and prognosis.

\section{Limitations:}

DWI interpretation should in conjunction with other morphological criteria in conventional MRI sequences.

\section{REFERENCES}

1. Grainger RG, Allison DJ. Imaging in Gynaecology in 'Grainger \& Allison's Diagnostic Radiology, A Textbook of Medical Imaging' 5th edition (Andy Adam, Adrian K. Dixon) ELSEVIER Churchill Livingstone. P.4,5; Ch.54, 2008

2. Whittaker C, Coady A, Culver L, et al. Diffusionweighted MR Imaging of Female Pelvic Tumors: A Pictorial Review. RadioGraphics2009; 29:759778.

3. Saremi F., Knoll AN, Bendavid OJ., SchultzeHaakh H., et.al., Characterization of Genitourinary Lesions with Diffusion-weighted Imaging (Abstract) by RadioGraphics, 29, 12951317. September 2009.

4. Pagani E, Bizzi A, Di Salle F, et al. Basic concepts of advanced MRI techniques. NeurolSci2008; 29:290-295.
5. Fujii S, Matsusue E, Kigawa J, Sato S, Kanasaki Y, NakanishiJ et al. Diagnostic accuracy of the apparent diffusion coefficient in differentiating benign from malignant uterine endometrial cavity lesions: initial results. Eur Radiol 2008;18:384-9.

6. Tamai K, Koyama T, Saga T, et al. Diffusionweighted MR imaging of uterine endometrial cancer. J MagnReson Imaging 2007; 26(3):682-687.

7. Silvera S, Oppenheim C, Touzé E, Ducreux D, Page P, Domigo V, Mas JL, Roux FX, Frédy D, Meder JF (2005) Spontaneous intracerebral hematoma on diffusion-weighted images: influence of T2-shine-through and T2- blackout effects. AJNR Am J Neuroradiol 26:236-241

8. Padhani A. R., Liu G., Mu-Koh D. et al., "Diffusion-weighted magnetic resonance imaging as a cancer biomarker: consensus and recommendations," Neoplasia, vol. 11, no. 2, pp. 102-125, 2009.

9. Thomassin-Naggara I, BazotM,Darai E, et al. Epithelial Ovarian Tumors: Value of Dynamic Contrast-enhanced MR Imaging and Correlation with Tumor Angiogenesis. Radiology 2009 ; 248: 148- 159.

10. Li W, Chu C, Cui Y, et al. Diffusion-weighted MRI: a useful technique to discriminate benign versus malignant ovarian surface epithelial tumors with solid and cystic components. Published online 2011 Oct 29

11. Bharwani N, Miquel, M., Sahdev A., Narayanan P., Malietzis G., et.al: Diffusion-weighted imaging in the assessment of tumour grade in endometrial cancer. Br J Radiol. Nov 2011; 84(1007): 997-1004.

12. Naganawa $S$, Sato $C h$, Kumada H, Ishigaki $T$, Miura Sh, Takizawa O. Apparent diffusion coefficient in cervical cancer of the uterus: comparison with the normal uterine cervix. Eur Radiol. 2005; 15: 71-8.

13. Chen J, Zhang Y, Liang B, Yang Z. The utility of diffusion-weighted $M R$ imaging in cervical cancer. Eur J Radiol. 2010; 74(3): e101-6

14. Chen YB, Hu CM, Chen GL, Hu D, Liao J. Staging of uterine cervical carcinoma: wholebody diffusionweighted magnetic resonance imaging. Abdom Imaging. 2010 (available online).

15. Morotti M, Valenzano M, John D, et al. The preoperative diagnosis of borderline ovarian tumors: a review of current literature. Arch GynecolObstet2011; 232-249. 


\section{الملخص العربى}

على الرغم من أن التشخيص النهائي للاور ام الخاصه بامر اض النساء يستند على الفحص الباثولوجي ، الألا انه من المفضل قبل

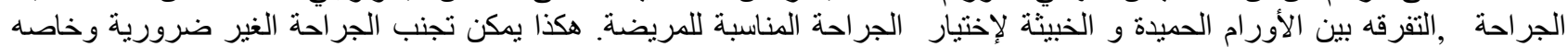

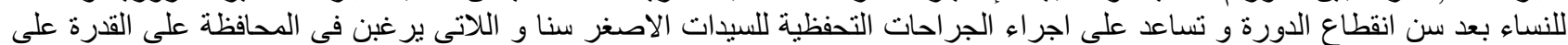

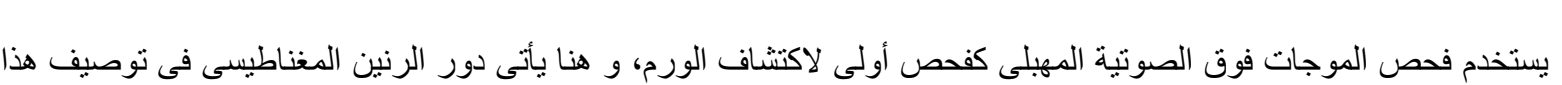

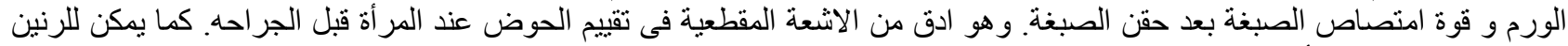

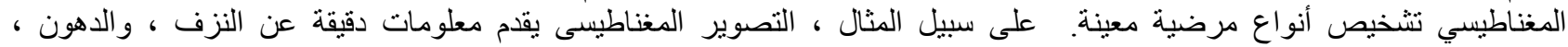

مع تطور التقنيات الحديثة فى التشخيص ، تم استحداث تقنيات جديدة للتصوير الوظيفى ، منهاالرنين المغناطيسي بالانتشار الجزيئي

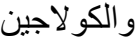

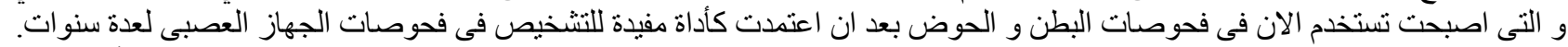

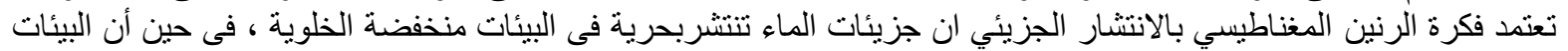

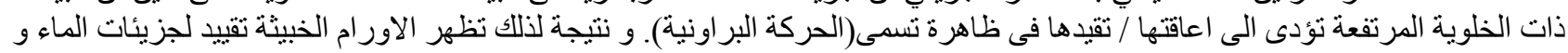

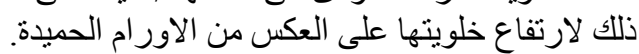

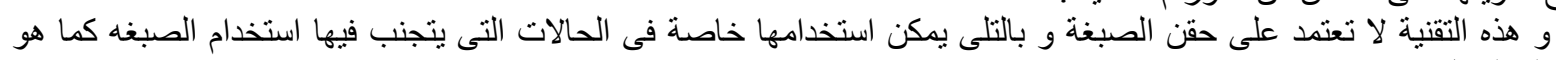

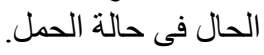
و قد استتجنا من هذه الدر اسة: إلى إن التصوير التقليدي بالرنين المغناطيسي مع إضافة الإنتشار الجزيئى :

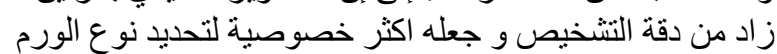

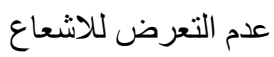
لا يتسبب في إطالة زمن الفحص لاع اون او زيادة تكلفته. و لكن من الأفضل إطبر إه مزيد من الدراسة مع عدد كبير من الحالات خاصة في أورام المبيض المشكوك فى نوعيتها. 